\title{
Reusing Geopolymer Waste from Matrices Based on Metakaolin or Fly Ash for the Manufacture of New Binder Geopolymeric Matrices
}

\author{
Rabii Hattaf ${ }^{1}$, Abdelilah Aboulayt ${ }^{1,2}{ }^{\oplus}$, Azzedine Samdi ${ }^{1}$, Nouha Lahlou ${ }^{3}$, Mohamed Ouazzani Touhami ${ }^{3}$, \\ Moussa Gomina ${ }^{4, *}$ and Redouane Moussa ${ }^{1}$ \\ 1 Laboratory of Physics and Chemistry of Inorganic Materials, Faculty of Sciences Aïn Chock, \\ University Hassan II Casablanca, Casablanca 53306, Morocco; rab.hattaf@gmail.com (R.H.); \\ aboulayt.abdelilah@gmail.com (A.A.); azdn.samdi@gmail.com (A.S.); redmoussa@yahoo.fr (R.M.) \\ 2 Materials Science, Energy and Nanoengineering Department, Mohamed VI Polytechnic University, \\ Lot 660-Hay Moulay Rachid, Benguerir 43150, Morocco \\ 3 Laboratory of Mechanics, Faculty of Sciences Aïn Chock, University Hassan II Casablanca, \\ Casablanca 53306, Morocco; nouhalahlou10@gmail.com (N.L.); touazzani2014@gmail.com (M.O.T.) \\ 4 CRISMAT UMR6508 CNRS, ENSICAEN, 6 boulevard Maréchal Juin, CEDEX 4, 14050 Caen, France \\ * Correspondence: moussa.gomina@ensicaen.fr; Tel.: +33-231451311
}

check for updates

Citation: Hattaf, R.; Aboulayt, A.; Samdi, A.; Lahlou, N.; Ouazzani

Touhami, M.; Gomina, M.; Moussa, R. Reusing Geopolymer Waste from Matrices Based on Metakaolin or Fly Ash for the Manufacture of New Binder Geopolymeric Matrices. Sustainability 2021, 13, 8070. https:// doi.org/10.3390/su13148070

Academic Editor: Nassim Sebaibi

Received: 27 May 2021

Accepted: 5 July 2021

Published: 20 July 2021

Publisher's Note: MDPI stays neutral with regard to jurisdictional claims in published maps and institutional affiliations.

Copyright: (c) 2021 by the authors. Licensee MDPI, Basel, Switzerland. This article is an open access article distributed under the terms and conditions of the Creative Commons Attribution (CC BY) license (https:// creativecommons.org/licenses/by/ $4.0 /)$.

\begin{abstract}
The increasing use of geopolymer materials in the construction and civil engineering sectors generates a large amount of non-biodegradable waste that will end up in landfills. It is therefore necessary to anticipate solutions for the proper management of this waste. In this work, new geopolymer materials were fabricated by partially replacing the reactive raw minerals (fly ash, FA, or metakaolin, MK) with used geopolymers (fully fly ash-based, FAref, or metakaolin-based, MKref), in order to develop a strategy to reuse geopolymer waste. Their workability and setting behavior were studied in the fresh state, and the geopolymerization process was investigated by calorimetry and by electrochemistry. Mechanical properties and the ability for coating mineral aggregates were assessed, and the resulting adhesion properties were analyzed using matrix/sand mortars. It appears that the new geopolymer materials as well as the mortars are endowed with good performances. The compressive strengths are above $50 \mathrm{MPa}$ and therefore meet the requirements of different construction materials. This demonstrates the recyclability of geopolymer materials. Moreover, an analysis of the influence of the substitution of recycled geopolymers on the setting and on the mechanical performances of mortars makes it possible to propose a binder-recycled geopolymer interaction model for the formation of new binding matrices.
\end{abstract}

Keywords: recycling; fly ash; metakaolin; waste; geopolymerization; mechanical characterization; binder-recycled geopolymer model

\section{Introduction}

Under demographic pressure, the building materials sector is booming. Among these manufactured materials, concrete is the most consumed, with a production of 6 billion cubic meters per year and an annual growth rate of $6.9 \%$. Concrete consists of a binding phase (cement) associated with aggregates and water. Cement is produced from a mixture of natural mineral raw materials (limestone and clay) brought to a very high temperature $\left(1450{ }^{\circ} \mathrm{C}\right)[1,2]$. Thus, this material has a heavy environmental and economic liability. Indeed, its production consumes huge tonnages of non-renewable fossil materials because its transformation requires heating to very high temperatures and, consequently, a big energy bill, and the decarbonation of limestone creating large emissions of $\mathrm{CO}_{2}$ gas and contributing to the greenhouse effect. The production of one ton of Portland cement requires 1.7 tons of raw materials and generates the emission of 0.85 tons of $\mathrm{CO}_{2}$ into the atmosphere [1-4]. This state of affairs has prompted the scientific community (researchers, 
civil engineers, etc.) to work for the creation of new binders for construction that are more respectful of nature. This is how geopolymer cements have emerged as very promising alternatives to Portland cement. These materials are generally produced by chemical reactions on some raw material rich in aluminosilicate compounds using an alkaline activating solution composed of sodium silicate and sodium or potassium hydroxide [5].

The synthesis process includes several stages: the dissolution of the raw material and formation of silicate and aluminate monomers, the formation of an oligomer gel, the polycondensation (formation of an amorphous three-dimensional network), and the hardening [6,7]. This process has many advantages: the materials harden at a very moderate temperature (below $100{ }^{\circ} \mathrm{C}$ ) with a reduced release of greenhouse gases. They have good mechanical properties (compressive strength up to $100 \mathrm{MPa}$ ) acquired largely during setting and at the start of hardening. They tolerate exposure to high temperatures, the most aggressive acids, and sulfates and chlorides as well. These characteristics open up a wide variety of application prospects in the field of construction materials: concrete, bricks, cladding materials, thermal and sound insulation panels, fire protection structures, protective coatings, etc. [8-12]. Another interesting aspect of these materials is that harmful industrial waste produced in large quantities can be incorporated into their composition. Among these wastes, fly ash issued from power plants, rice husk ash, slag from blast furnaces, red mud resulting from the manufacture of aluminum, phosphate mineral washing sludge, glass waste, construction and demolition waste, etc., figure prominently [13-19]. These wastes have the common factor of being composed of aluminosilicates, and therefore, they can be transformed by alkaline attack into value-added products, endowed with interesting technical properties and a high capacity of confinement of harmful elements such as heavy metals [20-22].

These technical, technological, and environmental advantages make it possible to gradually impose geopolymer materials against conventional building materials in the coming years. However, the increase in the production volume of these materials will generate huge quantities of non-biodegradable waste in the coming decades, either materials at the end of the life cycle or manufacturing waste stored in landfills. It is therefore necessary to develop several appropriate anticipatory strategies for the reuse of this type of waste.

The few existing works on the recycling of geopolymer waste can be analysed as per two approaches. The first one uses coarse-grained shredded waste, with the aim of replacing natural aggregates for the production of concrete or geopolymer mortars $[23,24]$. The second one uses waste with a finer grain size, with a view to substituting them for the starting aluminosilicate materials [25]. Thus, Akbarnezhad, A. et al. [23] studied the effect of replacing different amounts of natural aggregates with waste aggregates with sizes between 4.7 and $13.2 \mathrm{~mm}$ in a geopolymer concrete prepared from a mixture of kaolin, fly ash, and blast furnace slag (GGBFS) and activated by a sodium silicate solution. The total substitution of aggregates resulted in only 12.9, 10.7, and 15.2\% decreases in compressive strength, modulus of elasticity, and modulus of rupture, respectively. Zhu, P. et al. [24] studied the influence of the replacement of river sand by ground waste up to a grain size of around $3 \mathrm{~mm}$ for the production of metakaolin-based geopolymer mortars. The results showed that the mechanical strength of these mortars is unchanged up to substitution rate of about $50 \mathrm{wt} . \%$. It appears that this work was more focused on the reinforcing role played by the waste, in terms of the mechanical performance of the end products. However, they did not study in detail the interactions between the newly formed geopolymer phase and the recycled aggregates.

A second approach by Gharzouni, A. et al. [25] used finer-grained (less than $0.88 \mathrm{~mm}$ ) geopolymer waste powders as a substitute for metakaolin, the starting aluminosilicate. The results showed that the feasibility of these materials is limited to a substitution rate of about $20 \%$ and that the mechanical strengths of the final products decreased compared to the reference materials (without recycled geopolymer). 
Our contribution follows the same approach but is distinguished by the use of micronized waste powders of size less than $90 \mu \mathrm{m}$. The major advantage is to substitute large amounts (up to $50 \mathrm{wt} . \%$ ) of the starting aluminosilicates while maintaining good mechanical characteristics, comparable to those of the reference matrices free of waste. The other advantage is to allow the introduction of this waste during the geopolymer brick manufacturing process, for example, while maintaining the same processing parameters in the production chain (in terms of the nature and composition of the activation solutions, liquid/solid ratio, temperature, and curing time), which generates significant cost savings. The aim is to limit the massive consumption of non-renewable fossil resources and to reduce the negative impact of waste on the environment.

To this end, we first prepared two shades of geopolymer materials by activating fly ash (FA) and metakaolin (MK) using an alkaline solution composed of a mixture of silicate and sodium hydroxide. These materials were then stored for a year in the open air to simulate waste, and then were transformed into fine powders labelled FARG and MKRG, respectively. Furthermore, these powders were integrated as a substitute for the starting raw materials (MK and FA) in order to produce new geopolymer matrices. The influence of this substitution on the characteristics of the bricks in the fresh state (workability and setting kinetics) and in the hardened state (structural properties and mechanical resistance) is investigated in this work. Next, the suitability for coating standardized sand with these substituted matrices is studied. Then, the cohesion properties of the substituted matrix/standardized sand mortars with 30/70 mass ratios are evaluated. Finally, a phenomenological model is proposed to explain the interfacial mechanisms at the origin of the good adhesion properties between the reference matrices and the aggregates of geopolymer waste.

\section{Experimental Program}

\subsection{Materials, Equipment, and Methods}

The starting materials used for the development of geopolymer materials are:

- Commercial metakaolin (MK) of natural origin, rich in aluminosilicates, purchased from Imerys Argical M1000, France;

- Fly ash (FA) from Jarf Lasfar Thermal Power Plant, considered as industrial waste.

- Standardized sand used as aggregate for the fabrication of the mortars.

- An alkaline activating solution with $\mathrm{SiO}_{2} / \mathrm{Na}_{2} \mathrm{O}$ molar ratio $=1.2$ with 63 wt. $\%$ of water. It is a mixture of sodium hydroxide (purity $98 \%$ ), sodium silicate $\left(\mathrm{SiO}_{2} / \mathrm{Na}_{2} \mathrm{O}\right.$ with molar ratio $2.45 \%$ of dry matter), and water.

X-ray fluorescence and X-ray diffraction analyses are the two usual methods most suitable for determining the elemental and mineralogical composition of raw materials and materials such as clays, geopolymers, fly ash, cement, etc. They are timeless and have several advantages such as sensitivity, reproducibility, and the possibility of simultaneously analysing several elements and phases. In addition, these methods are commonly available, unlike inductively coupled plasma spectrometry, for example.

Quantitative chemical compositions of the starting materials were determined by X-ray fluorescence (Thermo ARL 9800XP). Attention was focused on the most abundant elements in mass in the powders, in particular those involved in the geopolymerization reaction such as: $\mathrm{SiO}_{2}, \mathrm{Al}_{2} \mathrm{O}_{3}, \mathrm{CaO}, \mathrm{Fe}_{2} \mathrm{O}_{3}, \mathrm{Na}_{2} \mathrm{O}$, and $\mathrm{K}_{2} \mathrm{O}$ (the elements with mass content of less than $0.01 \%$ were not reported). The XRF spectrometer used a $2.4 \mathrm{~kW} \mathrm{X-ray} \mathrm{tube}$ $(30 \mathrm{kV}$ and $80 \mathrm{~mA}$ ) with an analysis duration of $100 \mathrm{~s}$ for each sample. It was calibrated using certified reference material standards (CRMs) from the same matrix as the samples to be analyzed. For each element, a calibration curve was established, and correlation coefficients were determined by regression calculation. The content of the elements was evaluated by using ADVANTX-2252 instrument operating with v2.6.3.3985D of the OXSAS software (from Thermofisher ${ }^{\circledR}$, Waltham, MA, USA). The fusion method was considered for samples preparation, according to EN 196-2 standards which are widely used for major elements analyzes by XRF. To prepare the glass disc samples, $0.4 \mathrm{~g}$ of sample was 
homogenized and dried then mixed with $4 \mathrm{~g}$ of the dilithium tetraborate based fluxing agent (Spectroflux $100^{\circledR}$ ). The mixture was brought to complete melting in an electrical furnace for $1 \mathrm{~h}$ at $1000{ }^{\circ} \mathrm{C}$. After a periodic stirring, the homogeneous melted sample was recast into glass beads $2 \mathrm{~mm}$ thick and $32 \mathrm{~mm}$ in diameter. The quantitative chemical composition of the powders and the associated standard deviation are listed in Table 1.

Table 1. Quantitative chemical composition of the powders (LOI: loss on ignition).

\begin{tabular}{ccccccccccc}
\hline $\begin{array}{c}\text { Oxide } \\
\text { (wt.\%) }\end{array}$ & $\mathrm{SiO}_{2}$ & $\mathrm{Al}_{2} \mathbf{O}_{3}$ & $\mathrm{Fe}_{2} \mathbf{O}_{3}$ & $\mathrm{CaO}$ & $\mathbf{M g O}$ & $\mathrm{SO}_{3}$ & $\mathrm{Na}_{2} \mathbf{O}$ & $\mathbf{K}_{2} \mathbf{O}$ & $\mathbf{P}_{2} \mathbf{O}_{5}$ & LOI \\
\hline MK & 56.27 & 36.39 & 1.38 & 0.42 & 0.35 & 0.19 & 0.17 & 0.79 & 0.06 & 2.04 \\
\hline MKRG & 54.94 & 25.59 & 1.10 & 1.23 & 0.29 & 0.31 & 8.14 & 0.68 & 0.10 & 8.57 \\
\hline FA & 50.99 & 22.36 & 5.80 & 4.75 & 2.19 & 0.51 & 0.89 & 1.77 & 0.85 & 9.90 \\
\hline FARG & 46.23 & 17.04 & 5.39 & 5.36 & 2.09 & 0.55 & 6.52 & 1.64 & 0.57 & 12.88 \\
\hline Sand & 97.81 & 0.45 & 0.06 & 0.39 & 0.08 & 0.22 & 0.10 & 0.24 & 0.02 & 0.63 \\
\hline $\begin{array}{c}\text { Std. } \\
\text { deviation }\end{array}$ & \pm 0.03 & \pm 0.02 & \pm 0.07 & \pm 0.02 & \pm 0.01 & \pm 0.03 & \pm 0.01 & \pm 0.04 & - & \pm 0.05 \\
\hline
\end{tabular}

Mineralogical compositions were determined by using Bruker D8 Advance X-ray diffractometer equipped with $\mathrm{Cu} \mathrm{K} \alpha$ radiation source $(\lambda \mathrm{K} \alpha=1.5418 \AA)$ operating on $40 \mathrm{~mA}$ and $40 \mathrm{kV}$ with a scanning step of $0.02^{\circ}$ and a scanning rate of $10^{\circ} / \mathrm{min}$ in the range $10^{\circ}<2 \theta<70^{\circ}$ (Figure 1). The identification of the crystalline phases was made using version 2.1 of the DIFFRAC EVA software. We noted a displacement of the glassy domes towards the large angles for MKRG and FARG geopolymers compared to those of the raw materials MK and FA. This shift indicates that the geopolymerization reaction occurred through alkaline activation [25].

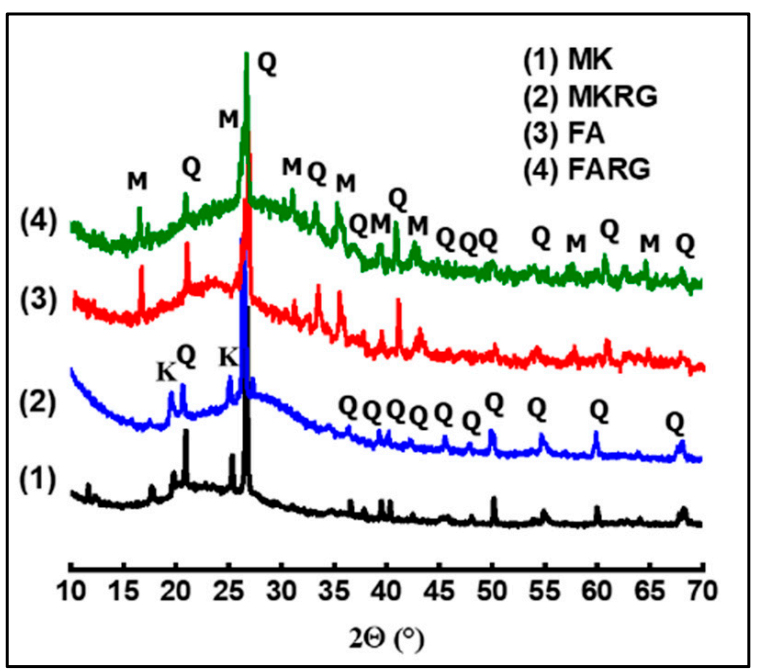

Figure 1. X-ray diagrams of the powders (Q: quartz (JCPDS 46-1045), M: mullite (JCPDS 15-0776), K: kaolinite (JCPDS 29-1488)).

The particle size distribution of the powders was determined by using a Mastersizer 2000 laser type analyzer (Malvern, UK) (Figure 2). The morphology of MK, FA, FARG and MKRG powders was revealed by using a Hirox MiniSem SH $4000 \mathrm{~m}$ type scanning electron microscope (Figure 3). 


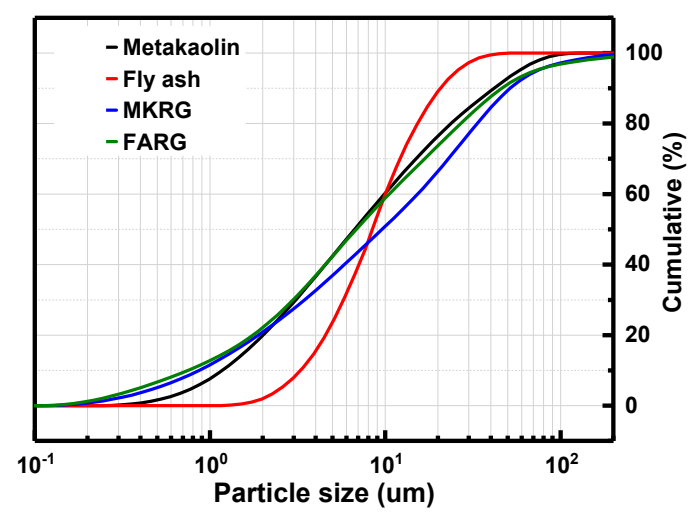

Figure 2. Grain size distribution of the powders.

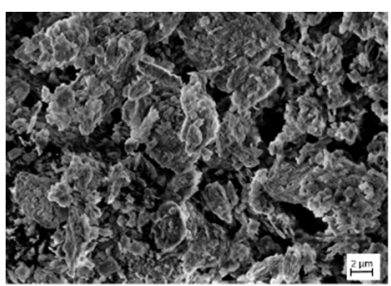

(a) $\mathrm{MK}$

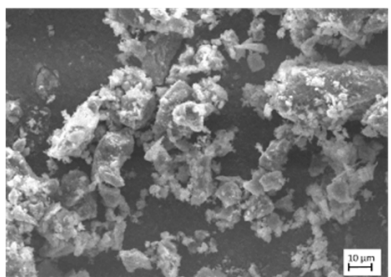

(c) MKRG

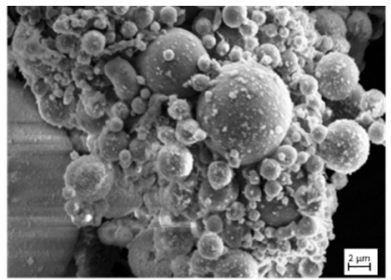

(b) FA

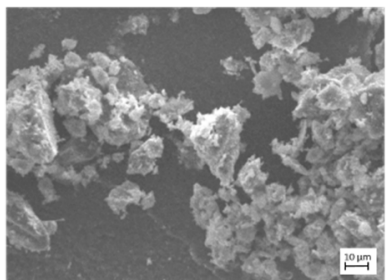

(d) FARG

Figure 3. SEM microphotographs of the powders: MK (a), FA (b), MKRG (c), and FARG (d).

\subsection{Formulation and Manufacturing}

Manufacturing the new materials involves two steps. In the first step, two shades of geopolymer materials, intended to simulate waste, were prepared. For the fly-ash-based geopolymer (FAref), the fly ash (FA) was mixed with a sodium silicate activating solution (SAS) with $\mathrm{SiO}_{2} / \mathrm{Na}_{2} \mathrm{O}$ molar ratio of 1.2 and $\mathrm{L} / \mathrm{S}=0.58$, then cured at $80^{\circ} \mathrm{C}$ for $20 \mathrm{~h}$. For the metakaolin-based geopolymer (MKref), metakaolin (MK) was mixed with a similar activating solution at $\mathrm{L} / \mathrm{S}$ ratio $=0.83$, and then cured at $60^{\circ} \mathrm{C}$ for $5 \mathrm{~h}$ (Table 2). Different curing times and temperatures were used due to the the difference in reactivity of these two powders with respect to the activation solution. Indeed, the morphology of the fly ash powder is relatively coarser, and its vitreous phase made up of glassy spherules is more energetically stable, while metakaolin powder is finer and the structure of its amorphous phase is formed of disorganized layers. This results in a higher reactivity. Therefore, the fly ash dissolution kinetic is slower than the metakaolin one and thus requires a higher temperature and a longer holding time. The materials obtained were stored for a year in the open air in order to simulate aging in an ambient environment [26]. They were then crushed using a roller mill, then sieved to obtain very fine powders of recycled geopolymers referenced FARG and MKRG for FA and MK, respectively. Mean grain size was less than $90 \mu \mathrm{m}$ for both recycled geopolymer powders, with size distribution comparable to the starting materials (MK and FA), see Figure 2. 
Table 2. Elaboration conditions of the fly-ash-based and metakaolin-based geopolymer materials.

\begin{tabular}{ccccc}
\hline Formulation & $\begin{array}{c}\text { Composition of } \\
\text { Alkaline Activation } \\
\left.\text { Sol. (SiO } \mathbf{~}_{\mathbf{2}} \mathbf{N a}_{\mathbf{2}} \mathbf{O}\right)\end{array}$ & $\begin{array}{c}\text { Liquid/Solid } \\
\text { Ratio (L/S) }\end{array}$ & $\begin{array}{c}\text { Curing } \\
\text { Temperature } \\
\left({ }^{\circ} \mathbf{C}\right)\end{array}$ & $\begin{array}{c}\text { Curing } \\
\text { Duration (h) }\end{array}$ \\
\hline FA/FARG & 1.2 & 0.58 & 80 & 20 \\
MK/MKRG & 1.2 & 0.83 & 60 & 5 \\
MK/FARG & 1.2 & 0.83 & 60 & 5 \\
\hline
\end{tabular}

The second manufacturing step relates to the preparation of the new binders by making mixtures between the starting materials, FA or MK, and the waste powders, FARG and MKRG. FA and MK were replaced by FARG and MKRG, respectively, at different mass contents (from 0 to $50 \%$ ). Three types of mixtures referenced as FA/FARG, MK/MKRG, and MK/FARG were prepared.

The mixtures were then subjected to activation under the same experimental conditions as preparing the formulation without waste. The materials made of FA/FARG mixtures were prepared by alkaline attack using a solution with $\mathrm{SiO}_{2} / \mathrm{Na}_{2} \mathrm{O}$ molar ratio of 1.2 and $\mathrm{L} / \mathrm{S}=0.58$, at $80^{\circ} \mathrm{C}$ for $20 \mathrm{~h}$ while MK/MKRG and MK/FARG mixtures were prepared by using a solution with $\mathrm{SiO}_{2} / \mathrm{Na}_{2} \mathrm{O}$ molar ratio of 1.2 and $\mathrm{L} / \mathrm{S}=0.83$, at $60{ }^{\circ} \mathrm{C}$ for $5 \mathrm{~h}$ (Table 2).

Finally, mortars were prepared by adding standardized sand aggregates to the pastes of the various aforementioned mixtures according to powder/sand mass ratio $=30 / 70$.

These global mixtures were transferred into moulds of dimensions $40 \times 40 \times 40 \mathrm{~mm}^{3}$ and were subjected to vibration for $5 \mathrm{~min}$ to remove the air bubbles. The moulds were wrapped in a polypropylene film to prevent the rapid evaporation of the water and were placed in an oven. After hardening, the samples were removed from the mould for storage at room temperature until the mechanical characterization $(3,7$, and 28 days).

\subsection{Characterization in the Fresh State}

The workability of the pastes was evaluated by measuring their viscosity at an early age at room temperature. The tests were carried out on a Haak Rheostress 1 type rotary rheometer fitted with a plane-plane geometry cell. The starting powder was mixed with the activation solution for three minutes. The paste was then placed on the rheometer plate and subjected to shear at a constant rate of $5 \mathrm{~s}-1$ for $2 \mathrm{~min}[27,28]$. The viscosity value is taken as the average of 5 measurements during this period.

The evolution of the setting was followed by two experimental techniques:

- Calorimetry by using a Netzsch STA 449 F3 Jupiter type calorimeter. After mixing the powder and the activation solution mixture for three minutes, the paste was placed in the crucible and then brought to the desired measurement temperature [7]. The heat exchange at constant temperature was thus recorded.

- Electrochemistry by using a GW INSTEK LCR-6101 type impedance analyzer. The test frequency was set at $1 \mathrm{kHz}$ under $1 \mathrm{~V}$ bias voltage. The paste was placed in a cell, in which two copper electrodes were immersed, connected in parallel with the impedance analyzer. The cell was placed in a thermostatically controlled bath set at $60{ }^{\circ} \mathrm{C}$ for MK-based pastes and at $80^{\circ} \mathrm{C}$ for FA-based pastes. The evolution of the conductivity of the medium as a function of time was thus recorded [29].

\subsection{Characterization in the Hardened State}

The mechanical properties of the binders and the mortars were determined after 3 , 7 , and 28 days of curing. The compression tests were carried out on a universal Perrier type testing apparatus equipped with a $200 \mathrm{kN}$ capacity load cell, following ASTM C109 standard [30]. For each condition, four specimens were tested, and the compressive strength was taken as the arithmetic mean of the four measurements. We also proceeded to the structural characterization of the materials by the determination of the apparent density and the water absorption according to the following method. After storage for 28 days, the 
samples were dried at $105^{\circ} \mathrm{C}$ for $72 \mathrm{~h}$ and then cooled down in air at room temperature. The dry mass was then measured ( $m_{d r y}$ in gram). Then, the samples were immersed in water for $72 \mathrm{~h}$ and the mass of the sample in the water ( $\mathrm{m}_{\text {wat }}$ in gram) was determined. Finally, the surfaces of these samples were dried before they are weighed in air $\left(\mathrm{m}_{\text {sat }}\right.$ in gram). Water absorption (WA) and apparent density were calculated respectively by the following Equations (1) and (2):

$$
\begin{gathered}
\text { WA }(\%)=100\left(\mathrm{~m}_{\mathrm{sat}}-\mathrm{m}_{\mathrm{dry}}\right) / \mathrm{m}_{\mathrm{dry}} \\
\rho_{\mathrm{g}}=\rho_{\mathrm{wat}} \mathrm{m}_{\mathrm{dry}} /\left(\mathrm{m}_{\mathrm{sat}}-\mathrm{m}_{\mathrm{wat}}\right)
\end{gathered}
$$

where $\rho_{\mathrm{g}}$ is the apparent density of the geopolymer in $\mathrm{g} / \mathrm{cm}^{3}$ and $\rho_{\mathrm{wat}}$ is the apparent density of water in $\mathrm{g} / \mathrm{cm}^{3}$.

Macro and microstructural observations of the materials were implemented by using a ZHX-700F type digital optical microscope (Keyence, Osaka City, Japan) in order to assess the morphology and the quality of the matrix/aggregates interface.

\section{Results and Discussion}

\subsection{Workability}

The workability of a paste expresses its aptitude for shaping (casting, molding, etc.). A comparative study of the workability of the pastes was carried out by determining their viscosity at a short-term period after mixing.

Figure 4 represents the change in viscosity of the pastes as a function of the content of recycled geopolymer. It can be first noted that the metakaolin-based paste, MKref (without substitution), shows a viscosity of 41.85 Pa.s, which is significantly higher than that of the fly-ash-based paste, FAref (without substitution), whose value is $31.66 \mathrm{~Pa}$.s. However, the metakaolin-based paste had a liquid to solid ratio higher than the ash-based paste, i.e., 0.83 versus 0.58 . This can be explained by the difference in the water demand of these powders. The water demand depends on the specific surface of the aggregates and their morphology. The higher viscosity of the MK-based paste is assigned to its peculiar structure, which derives from the layered structure of the kaolinite (the initial ore) and is characterized by a large specific surface area and therefore a high water demand, unlike fly ash, which shows spherically shaped aggregates and larger particle sizes (Figures 2 and 3a,b) [6].

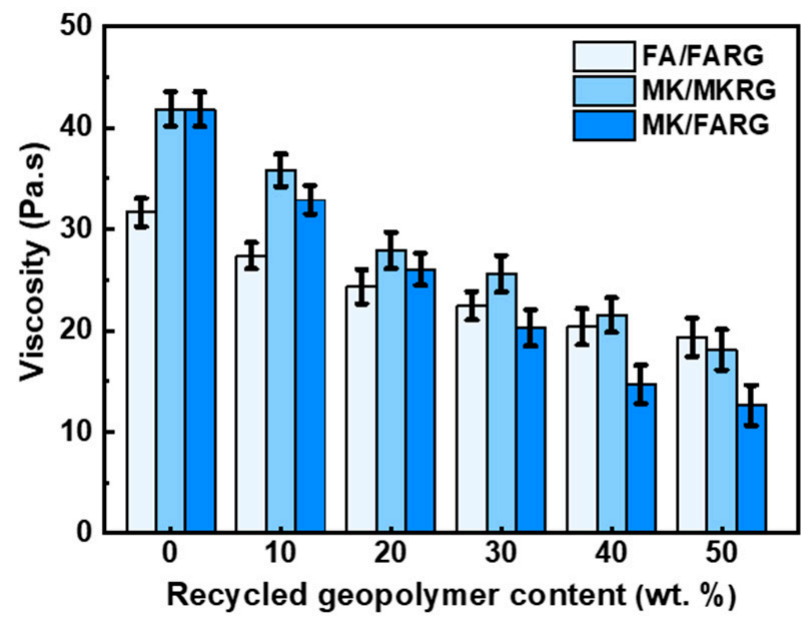

Figure 4. Variation of the viscosity of the pastes as a function of the substitution rate of recycled geopolymer.

It is also noted that whatever the formulation considered, the increase in the recycled geopolymer content results in a decrease in viscosity, which means an improvement in workability. This reduction in viscosity is assigned to the gradual replacement of reactive aluminosilicate powder (MK or FA) with respect to the activation solution by more 
chemically inert additives characterized by lower water absorption (FARG and MKRG) [25]. This leads to a reduction in the amount of silicate and aluminate monomers produced after dissolution and therefore a decrease of the oligomers produced in the medium is noted. These species are responsible for gel formation which explains the viscosity of the pastes in the early period of the alkaline attack $[27,31,32]$. This trend was reported in previous works when reactive aluminosilicate compounds such as fly ash or metakaolin were replaced by chemically inert aggregates such as sand or glass waste [32-36].

\subsection{Investigation of the Geopolymerization Process}

\subsubsection{Calorimetry}

Calorimetry tests were carried out on FA/FARG, MK/MKRG, and MK/FARG at $60{ }^{\circ} \mathrm{C}$ for metakaolin-based mixtures and $80^{\circ} \mathrm{C}$ for fly-ash-based mixtures. The objective was to study the effect of adding recycled geopolymers on the heat exchange during the geopolymerization process.

The results shown in Figure 5 indicate the same behavior for the three formulations in terms of the influence of the substitution rate. Three distinct events are worth noting:

- $\quad$ The occurrence of a first exothermic peak from the very first moments (domain I) is attributed to the wetting and dissolution of the reactive aggregates. The alkaline attack destroys the bonds within the amorphous phase and produces monomers, thereby generating heat exchange $[7,37,38]$. The amplitudes of the peaks of the reference materials MKref and FAref (without additives) are the highest. For each of the three formulations, the amplitude gradually decreases as the content of added recycled geopolymer is increased. This trend can be explained by the increasing substitution of FA and MK, which contain amorphous phases that are very reactive towards the activation solution, taking into account the curing temperature $[29,39,40]$, by recycled geopolymers which are weakly or not at all reactive under these conditions [25].

- $\quad$ A second event (domain II), also exothermic, is attributed to the structuring phenomenon, i.e., the massive precipitation of the products issued from the activation reaction $[22,37,38]$. On the one hand this phenomenon is delayed when the substitution rate of the reactive materials $\mathrm{MK}$ and FA is increased. This means that as the amounts of these materials are reduced, the amounts of the monomeric silicate and aluminate species produced by dissolution decreases, hence the time necessary for oversaturation in aluminosilicate oligomers and to trigger polycondensation is extended. On the other hand, this delay correlates to the heat exchanged, which demonstrates that the polycondensation rate decreases, and as a result, the global heat exchanged is also reduced when the content of recycled geopolymers is increased [22,37,38,41].

- Finally, the reduction in heat generation indicates that the setting process by the formation of a three-dimensional network is attenuated (domain III); its stabilization indicates that the structuring phenomenon is ending.

It is clear that the substitution of recycled geopolymers for much more reactive mineral materials has a delaying effect on the setting.

\subsubsection{Electrochemical Measurements}

Electrochemical measurements were implemented to precisely determine the instants of the beginning and end of the setting of the pastes via the time evolution of the electrical conductivity (Figure 6). As for calorimetry measurements, the variation in conductivity as a function of the rate of substitution of the recycled geopolymer shows the same trend, independent of if the formulation considered is FA/FARG, MK/FARG, or MK/MKRG. These curves also present the following three domains of behavior [29]: 

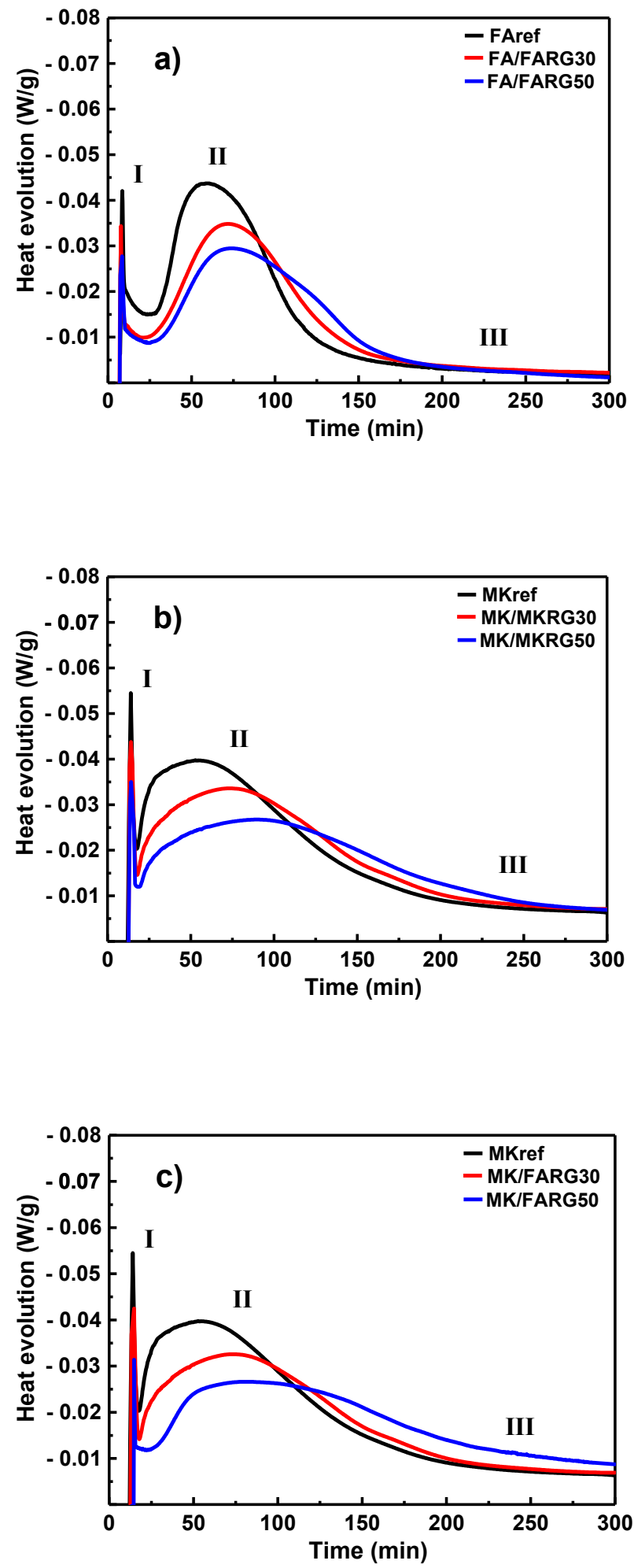

Figure 5. Variation of the heat exchange as a function of the substitution rate of recycled geopolymer: FA/FARG (a), MK/MKRG (b), and MK/FARG (c).

- A first domain identified by the rapid increase in conductivity toward a maximum value is assigned to the combined action of two phenomena: the dissolution of raw materials by the alkaline attack and the action of temperature. In fact, the alkaline attack products are charged monomers whose mobility increases when the temperature of the mixtures is increased from the ambient temperature (during mixing) to the 
test temperature $\left(60{ }^{\circ} \mathrm{C}\right.$ for metakaolin-based suspensions and $80{ }^{\circ} \mathrm{C}$ for those that are fly-ash-based)

- The second domain is called the "oversaturation stage" (maximum conductivity values) in which the conductivity is almost constant due to a balance between the dissolution and polycondensation processes.

- In the third domain, the drop in conductivity is explained by the polymerization process (the start of setting by massive precipitation after saturation of the medium in aluminate and silicate species), which takes precedence over dissolution. Indeed, the precursors reorganize by immobilizing the alkaline cations $\mathrm{Na}^{+}$. These cations act as charge compensators in the geopolymer network and are mainly responsible for the conductivity of the medium. Their immobilization is manifested by a continuous decrease in conductivity toward a stable level which indicates the end of the geopolymerization process, i.e., the end of setting.
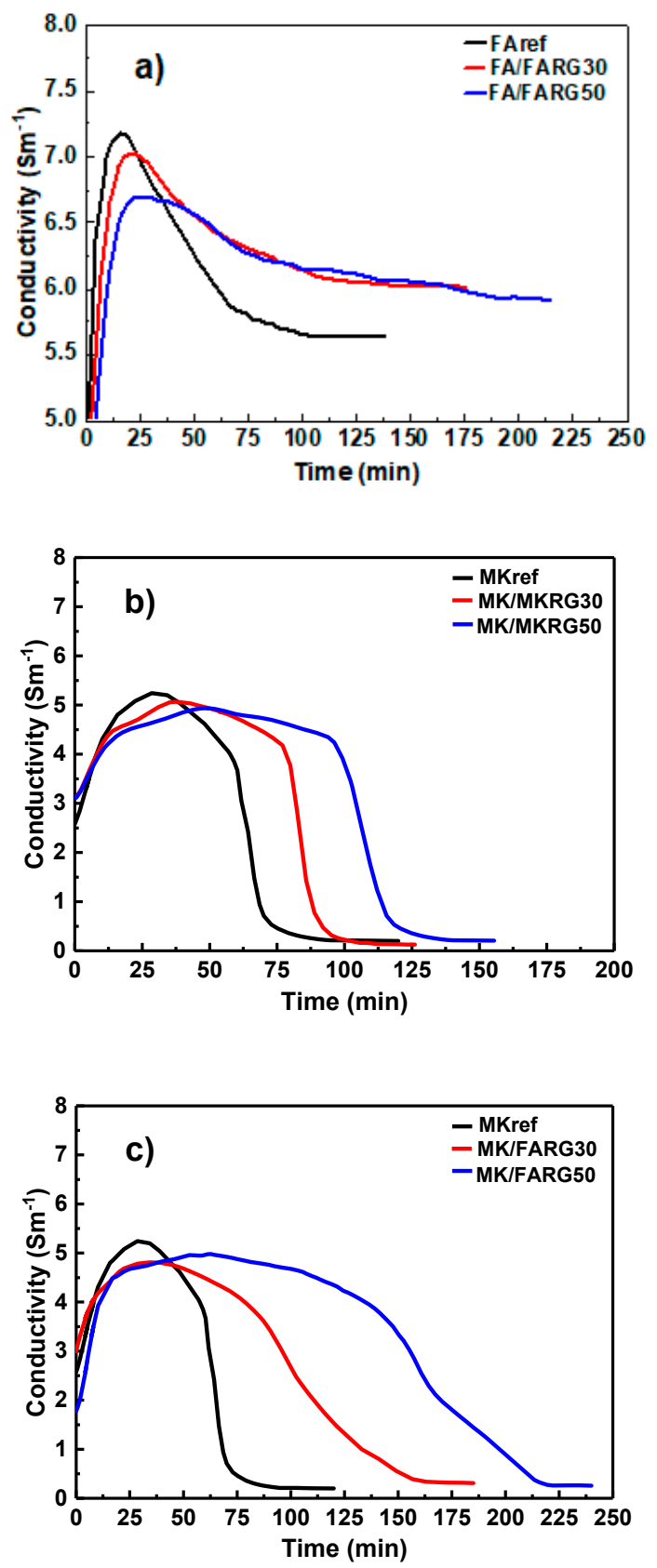

Figure 6. Variation of the conductivity as a function of the substitution rate of recycled geopolymer: FA/FARG (a), MK/MKRG (b), and MK/FARG (c). 
It is noted that the electrochemistry results are in good agreement with the calorimetry results.

Regardless of the formulation, the least reactive mixtures (i.e., those containing the highest substitution rates of recycled geopolymer) take longer before polycondensation predominates. That means that the amounts of the silicate and aluminate monomer species produced by dissolution are not sufficient to trigger massive polycondensation, which explains the existence of an extended second phase plateau. In fact, the degree of geopolymerization increases when the rate of the reactive raw material is raised, which leads to the acceleration of gel formation and the structuring of the geopolymer [22,37].

Thus, the consumption of charge-compensating sodium cations is accelerated, and consequently, the start $\left(t_{s}\right)$ and end $\left(t_{e}\right)$ times of setting are reduced [29] (Table 3).

Table 3. Start $\left(t_{i}\right)$ and end $\left(t_{f}\right)$ time of setting of the materials.

\begin{tabular}{ccccccccc}
\hline & FAref & FA/FARG30 & FA/FARG50 & MKref & MK/MKRG30 & MK/MKRG50 & FA/MKRG30 & MK/FARG50 \\
\hline $\mathrm{t}_{\mathrm{i}}(\mathrm{min})$ & 18.04 & 23.64 & 36.41 & 34.92 & 42.20 & 54.31 & 42.97 & 70.17 \\
$\mathrm{t}_{\mathrm{f}}(\mathrm{min})$ & 112.94 & 143.3 & 188.29 & 88.92 & 105.09 & 134.17 & 164.58 & 219.19 \\
\hline
\end{tabular}

\subsection{Structural and Mechanical Characterization in the Hardened State}

\subsubsection{Structural and Mechanical Characterization of the Binders}

The evolution of the compressive strength of the binders FA/FARG, MK/MKRG, and MK/FARG at 3, 7, and 28 days of curing is shown in Figure 7.

Whatever the composition of the mixtures, the hardened materials seem to reach a maximum level after only 3 days of curing. This trend is explained by the high reactivity of FA and MK under the effect of the activation solution and the curing temperature. It is well known that a higher curing temperature and the optimal activation solution composition enhances the degree of geopolymerization, which promotes strength development at an early age $[29,40,42,43]$. For all three matrices, the compressive strength is unchanged for curing time between 3 and 28 days for substitution rates up to $40 \mathrm{wt} . \%$. Reference materials FAref and FA/FARG40 have compressive strengths of 53.46 and $52.23 \mathrm{MPa}$, respectively, while those of MKref, MK/MKRG40, and MK/FARG40 are 63.3, 59.2, and $58.8 \mathrm{MPa}$, respectively. Beyond a substitution rate of $40 \mathrm{wt} . \%$, the compressive strength at 28 days decreases by about $20 \%$ compared to the reference matrices of FAref and MKref (43.4, 50.0, and 48.7 MPa for FA/FARG50, MK/MKRG50, and MK/FARG50, respectively). These changes are well correlated with the density and water absorption rate (Figure 8) whose values vary significantly beyond the rate of $40 \mathrm{wt} . \%$. In fact, the resistance of a composite material is governed by several factors such as the volume and the resistance of the binding matrix, that of the aggregates, the matrix-aggregates bond... [38,44]. The good mechanical behavior of these materials up to $40 \mathrm{wt} . \%$ substitution suggests a fairly good bond between the binding matrices formed after the activation of the aluminosilicate sources (FA or MK) and the recycled geopolymers (FARG or MKRG). The decrease in compressive strength beyond $40 \mathrm{wt} . \%$ additive is attributed to the reduction in the amount of reactive raw material, and therefore to the reduction in the volume of the newly formed geopolymer phase, which results in loss of densification and manifests itself in an increase of the water absorption (Figure 8). 

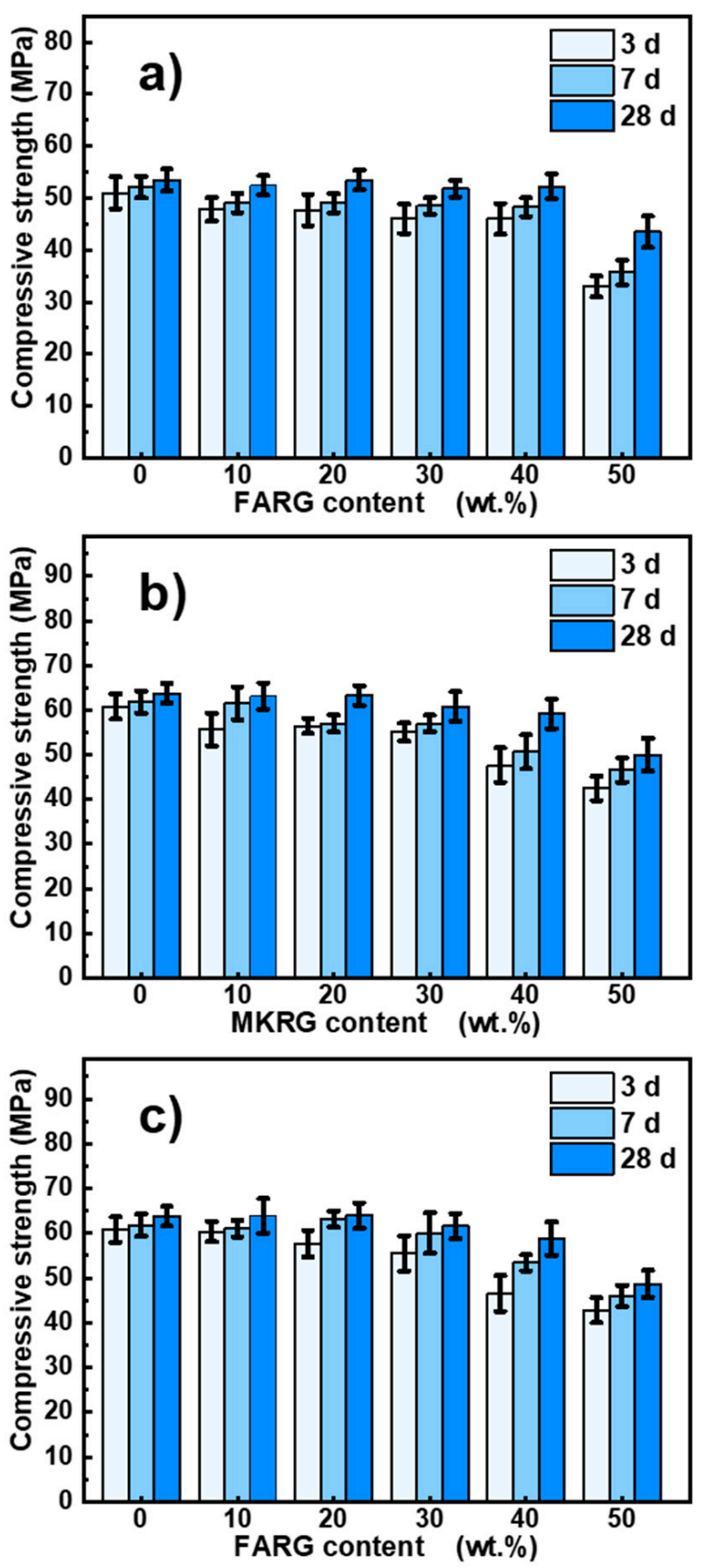

Figure 7. Variation of the compressive strength of the binders at 3,7 , and 28 days of cure as a function of the substitution rate of recycled geopolymer: FA/FARG (a), MK/MKRG (b), and MK/FARG (c).

The observation of the surfaces of rupture by scanning electron microscopy (Figure 9) confirms the mechanical characterization. The newly formed geopolymer phase cannot be differentiated from that of the substitution waste, and the fracture surfaces of the reference matrices are similar to those of the $50 \%$ by weight substituted material aggregates. These data confirm the quality of the new binders and the good cohesion between the two constituents. The fracture surfaces of FAref and FA/FARG50 are inhomogeneous, marked by the presence of spherules or impressions of vitreous spherules originating from the raw material, which did not react to alkaline attack (Figure 9a,b). On the other hand, the fracture surfaces of MKref, MK/MKRG50, and MK/FARG50 (Figure 9c-e) seem more homogeneous and more compact, which may explain their relatively higher compressive strength. 

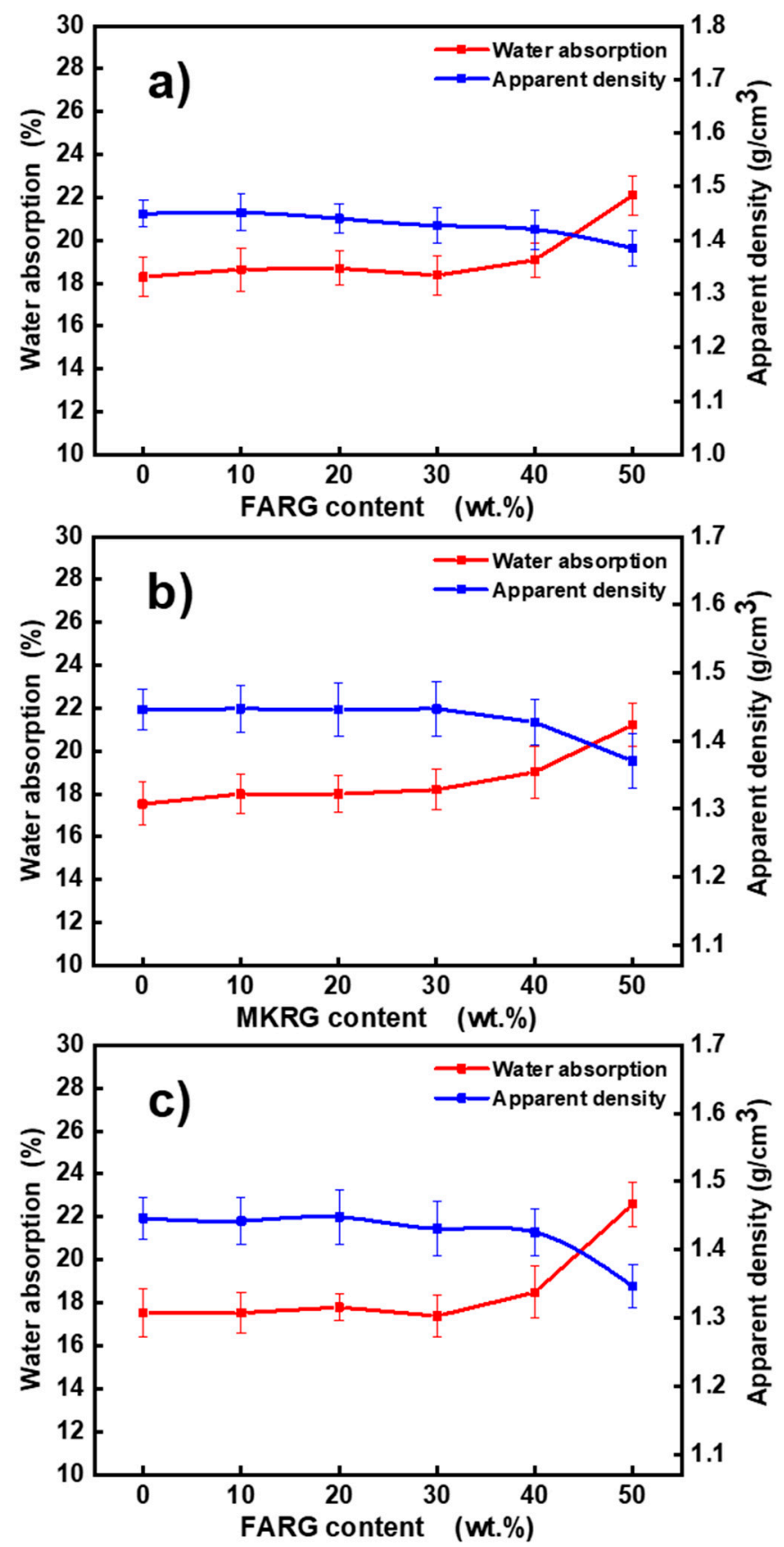

Figure 8. Variations of water absorption and density of the binders as a function of the substitution rate of recycled geopolymer added: FA/FARG (a), MK/MKRG (b), and MK/FARG (c).

Figure 10 shows the diffractograms of FA/FARG, MK/MKRG, and MK/FARG after 28 days of cure. It is obvious that the spectra of the two materials FA/FARG (Figure 10a) and MK/MKRG (Figure 10b) overlap perfectly with those of the reference geopolymers FAref and MKref, respectively. This indicates that no new crystalline phase was formed during exposure of the reference materials to ambient conditions for 1 year. FA/FARG materials are composed of quartz and mullite, which are inert phases originating from the alkaline attack of fly ash, and of an amorphous phase identified by the glassy dome located in the angular range $20^{\circ}<2 \theta<35^{\circ}$. MK/MKRG materials consist of quartz, traces of residual kaolinite not transformed by the heat treatment applied to obtain the kaolin, and of an amorphous phase. On the other hand, MK/FARG blends (Figure 10c) are composed of the MK reference matrix (characteristic lines of quartz and residual kaolinite) and mullite (glassy dome formed from FARG waste). 


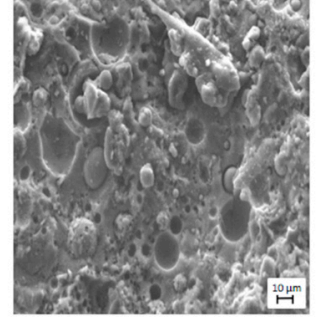

(a) FAref

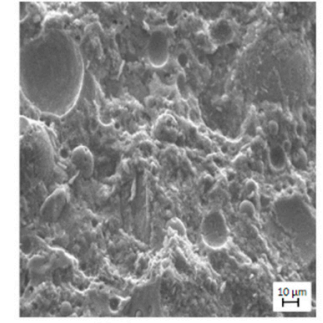

(b) FA/FARG50

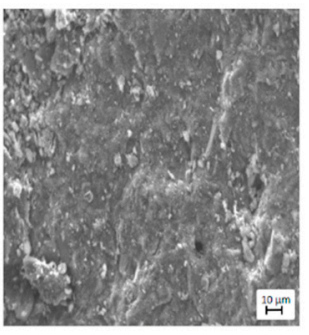

(c) MKref

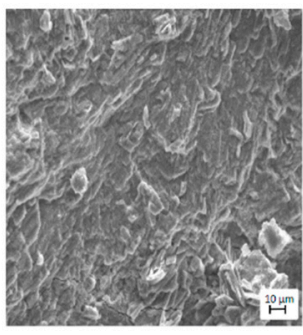

(d) MK/MKRG50

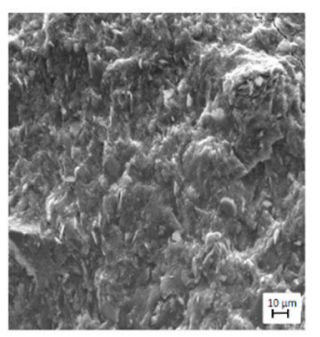

(e) MK/FARG50

Figure 9. Fracture surfaces of the binders: FAref (a), FA/FARG50 (b), MKref (c), MK/MKRG50 (d), and MK/FARG50 (e).
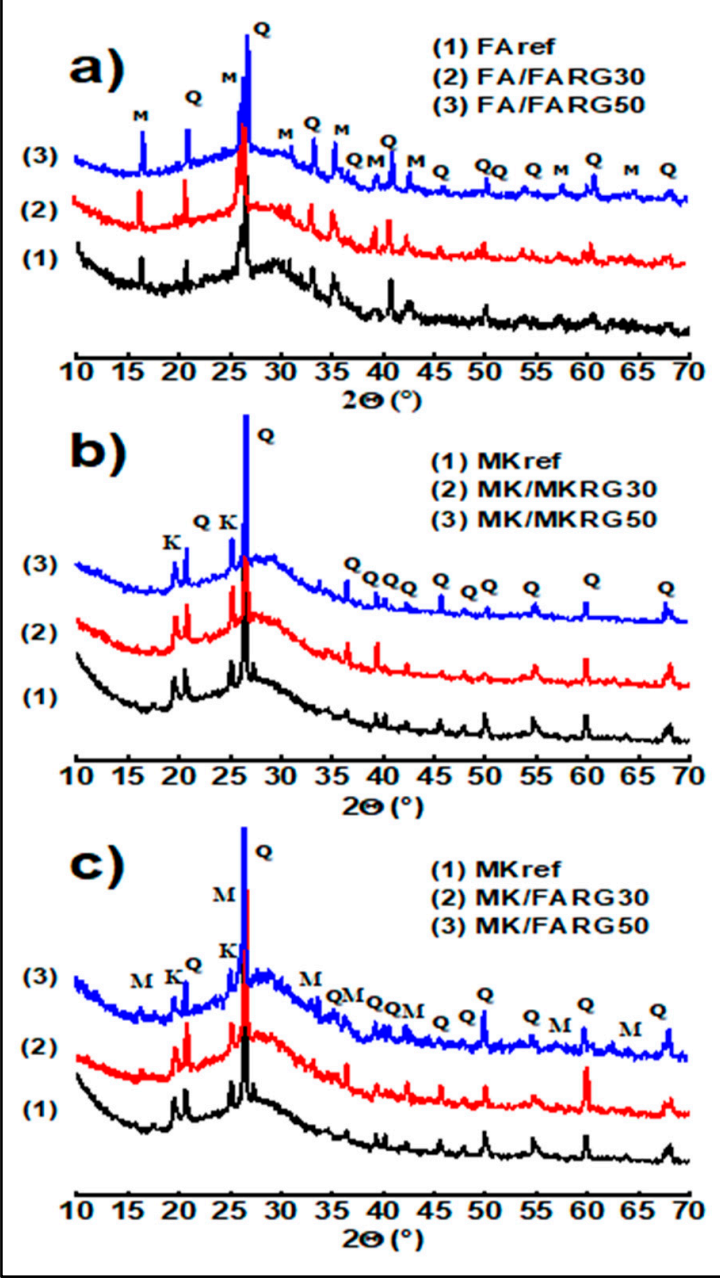

Figure 10. X-ray diagrams of the binders: FA/FARG (a), MK/MKRG (b), and MK/FARG (c) (Q: quartz, M: mullite, K: kaolinite). 


\subsubsection{Structural and Mechanical Characterization of Mortars}

Mortars were fabricated and characterized with the aim to evaluate the binding capacity of the new geopolymers and their adhesion ability with mineral aggregates. They consist of $30 \mathrm{wt} . \%$ of raw material FA or MK and recycled geopolymer, and $70 \mathrm{wt} . \%$ of standardized sand. The specimens thus produced were tested by uniaxial compression at 3 , 7 , and 28 days of cure. The results presented in Figure 11 indicate that the addition of sand slightly improved the compressive strength compared to the unfilled matrices (Figure 7). This beneficial effect had been reported by other authors [45-48]. The addition of a filler (granular phase like sand) to a binding matrix improves its compactness, homogenizes the stress distribution, helps stabilize the cracks, and therefore, increases the work of fracture.
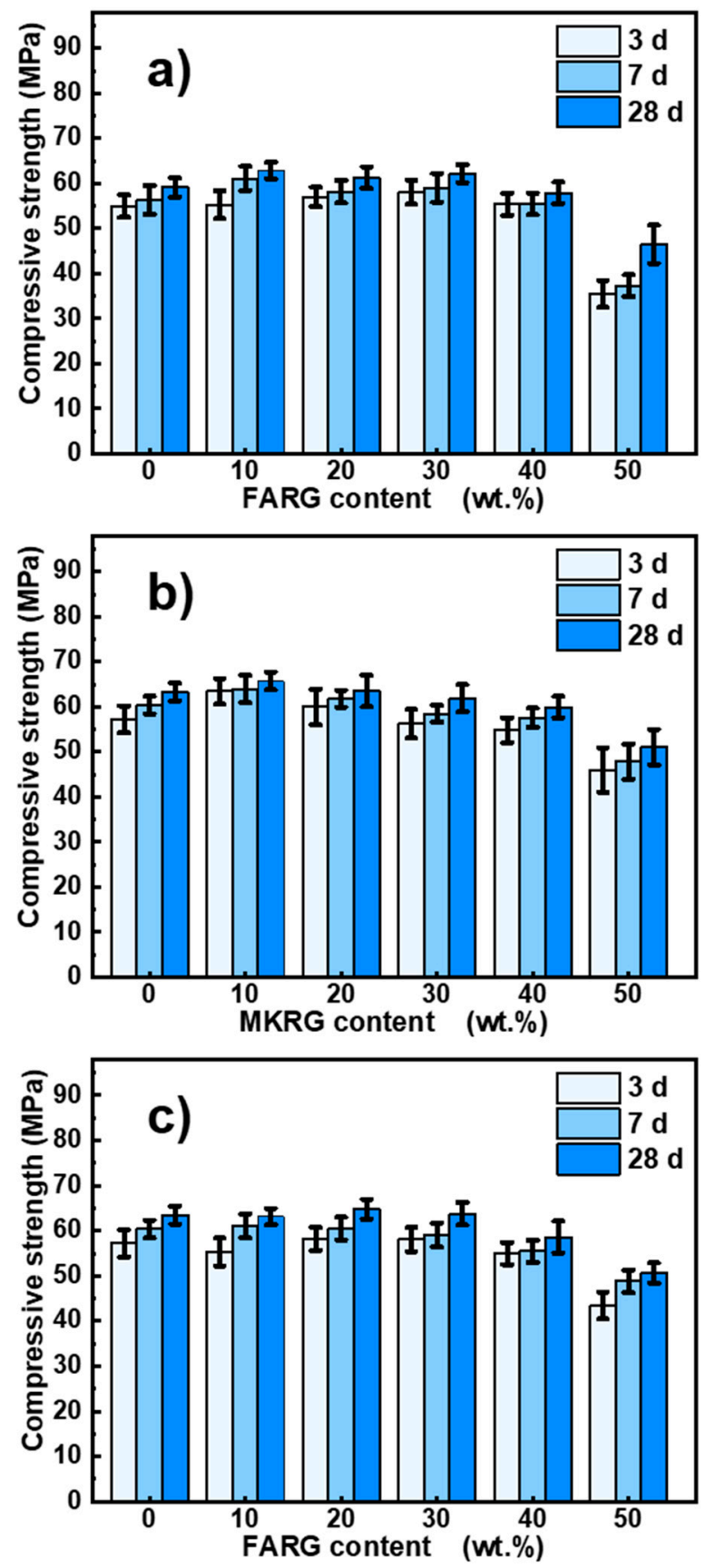

Figure 11. Variation of the compressive strength of the mortars at 3, 7, and 28 days of cure as a function of the substitution rate of recycled geopolymer: FA/FARG (a), MK/MKRG (b), and MK/FARG (c). 
The increase in the substitution rate up to $40 \mathrm{wt} . \%$ does not significantly modify the compressive strength of the mortars. Compressive strengths of 59.1 and $58.0 \mathrm{MPa}$ were obtained for FAref and FA/FARG40 matrix mortars, respectively, while the values for MKref, MK/MKRG40, and MK/FARG40 matrix mortars are 63.5, 59.95, and 58.9 MPa, respectively. At $50 \mathrm{wt}$ \% substitution, the compressive strengths of the mortars decrease by about 20\% compared to the FAref and MKref reference mortars $(46.5,51.1$, and 50.7 $\mathrm{MPa}$ for FA/FARG50, MK/MKRG50, and MK/FARG50 matrices, respectively).

These results prove that the rupture is mainly governed by the binding matrix, which confirms the presence of a strong bond between the newly formed geopolymer phase (formed by polycondensation of the oligomers obtained by dissolution of MK or FA) and the recycled geopolymer aggregates (FARG or MKRG), and that the set of matrices (newly formed geopolymer-recycled aggregates) then behaves as a single binding matrix. It is worth noting that even for these high substitution rates, this binding matrix retains a good binding capacity and good matrix-sand aggregate adhesion as it appears in Figure 12. These micrographs show that the coating quality of the binding matrices mixed with $50 \mathrm{wt}$ \% substitution of recycled geopolymer is comparable to that of the reference matrices FAref and MKref.

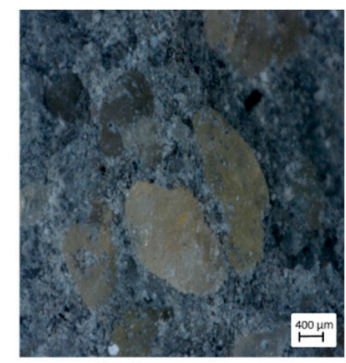

(a) FAref

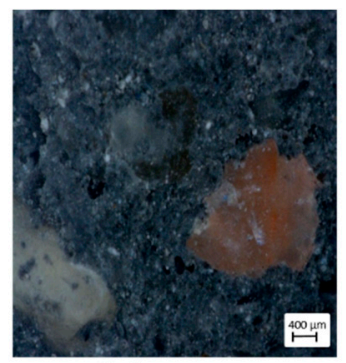

(b) FA/FARG50

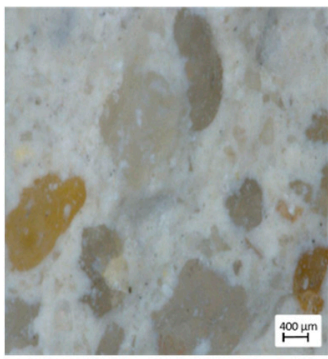

(c) MKref

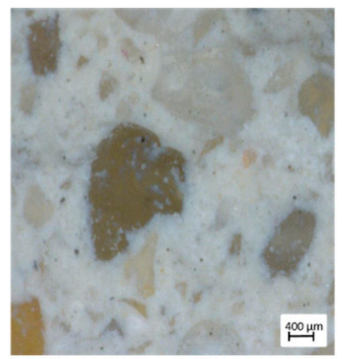

(d) MK/MKRG50

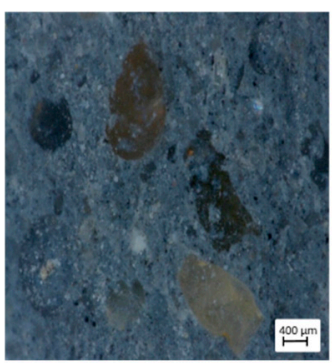

(e) MK/FARG50

Figure 12. Digital optical photographs of the mortars: FAref (a), FA/FARG50 (b), MKref (c), MK/MKRG50 (d), and MK/FARG50 (e).

3.3.3. Newly Formed Geopolymer-Recycled Geopolymers Anchorage by Interfacial Chemical Interaction

The summary of the results obtained in the fresh state by monitoring the workability and the geopolymerization process shows that the powders of recycled geopolymers are chemically inert or weakly reactive with respect to the alkaline solution. In the hardened state, it appears that the substitution of the raw materials FA and MK for the recycled geopolymers FARG and MKRG up to the rate of $50 \mathrm{wt} \%$ does not affect either of the structural characteristics. This is confirmed by the SEM observations of the fracture surfaces that show features similar to those of the reference matrices, which do not make it possible to distinguish the recycled geopolymers from the newly formed geopolymers. This is accompanied by a slight decrease in mechanical strength (less than $20 \%$ ), with a mean value around $48 \mathrm{MPa}$. After the introduction of sand aggregates for the preparation of mortars, one could expect a drop in mechanical strength. Indeed, the proportion of reactive aluminosilicate powder (metakaolin or fly ash) is low and only represents $15 \%$ by mass of all the solid materials in the mixture (sand, reactive aluminosilicate powder, and 
recycled geopolymer powder). However, mortars have high mechanical strengths (around $50 \mathrm{MPa}$ ). This finding confirms the strong cohesion of the recycled geopolymer-a newly formed geopolymer phase entity, which behaves similar to a unique binding matrix. In a study on materials consisting of geopolymer matrices based on metakaolin and glass beads aggregates, Zhang, L. et al. [44] attributed the good mechanical strength to the creation of a chemical bond at the matrix-filler interface. The amorphous structure of these glasses and their composition based on silicon and aluminum have similarities with those of geopolymers and their reactivity in the presence of the activating solution. These data prompted us to propose a model that represents the interfacial interaction between newly formed geopolymer and the aggregates of recycled geopolymers (Figure 13), which can be described as follows. The alkaline activation dissolves the reactive materials MK and FA to form aluminosilicate oligomers. The reaction of these with the chemical species present on the surface of the recycled geopolymer aggregates leads to the formation of chemical bridges. A gel then forms, which will gradually develop with the polycondensation to stick the aggregates together. The set of newly formed geopolymers and the recycled aggregates then behave as a single binding matrix.

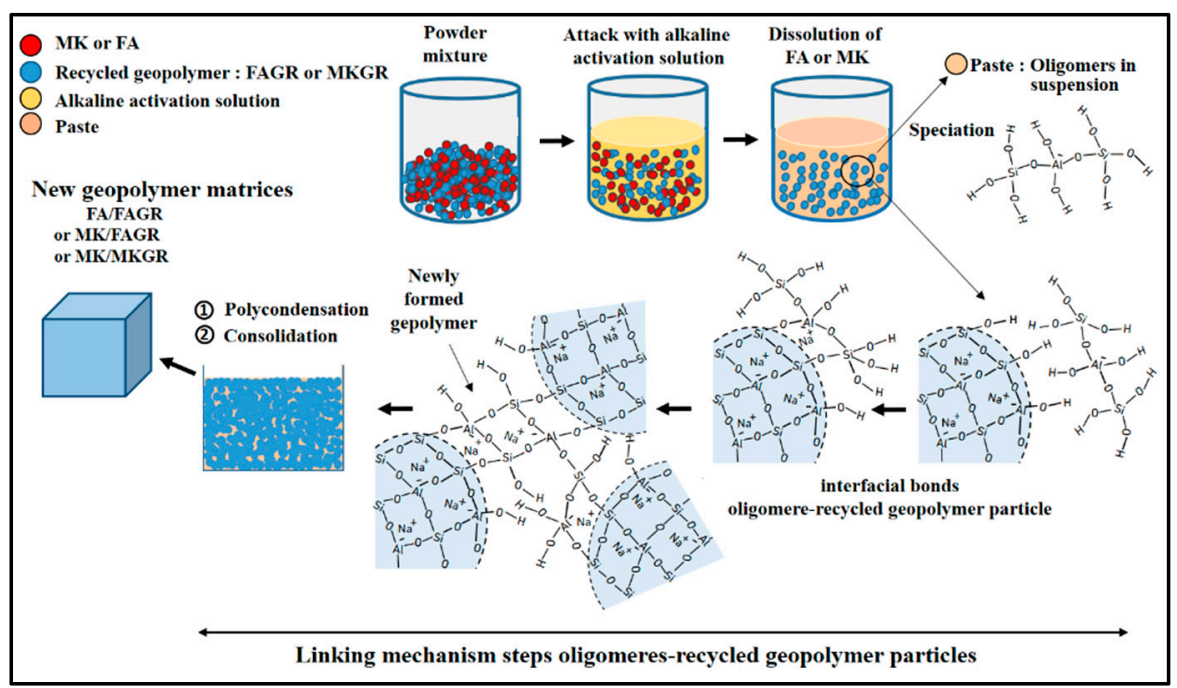

Figure 13. Modeling of the chemical interaction process at the interfaces between the newly formed geopolymer and the recycled geopolymer.

The newly formed oligomer gel therefore appears to be the factor responsible for the cohesion at the matrix-aggregate interface. The increase in the substitution rate of active aluminosilicate materials by recycled geopolymers has the effect of lowering the concentration of oligomers in the medium, with the consequences of less interfacial bonds and the observed reduction in the mechanical strength of the materials.

\section{Conclusions}

The goal of this work was to contribute to the preservation of resources in mineral raw materials by reducing massive exploitation of natural materials rich in aluminosilicates such as metakaolin. To this end, geopolymer wastes (FARG and MKRG) were used in the partial replacement of metakaolin (MK) or fly ash (FA) for the fabrication of three new matrices by alkaline activation (FA/FARG, MK/MKRG, and MK/FARG). The influence of the substitution of geopolymer waste on the physicochemical and mechanical characteristics of these new geopolymers was checked up to a rate of $50 \mathrm{wt} . \%$. The main lessons that emerge are as follows:

- The substitution improves the workability of the mixtures. Increasing the substitution rate to the detriment of reactive raw materials reduces the amount of oligomers 
produced. These species are at the origin of the gelation phenomenon which is responsible for the increase in viscosity of the mixtures at an early age.

- The setting phenomenon was studied by electrochemistry and by calorimetry. Both series of results are in agreement on the delaying effect observed when the substitution rate of recycled geopolymers is increased, as they are more chemically inert under the activation conditions (alkalinity and temperature). Reducing the amount of the most reactive materials lowers the rate of the silicate and aluminate monomer species formed after dissolution in the medium and therefore extended the time necessary for oversaturation of the aluminosilicate oligomers, the initiation of polycondensation, and the end of the geopolymerization process.

- For all the binders investigated, high compressive strengths are generally maintained for substitution rates up to $40 \mathrm{wt} . \%$ (about $60 \mathrm{MPa}$ for metakaolin-based binders and $52 \mathrm{MPa}$ for fly-ash-based binders). That suggests a strong cohesion between the newly formed matrix and the recycled geopolymer aggregates.

- The characterization of mortars made of the new matrices and $70 \mathrm{wt} . \%$ of standardized sand shows the good bonding capacity of these matrices, with a beneficial effect on the compressive strength. Finally, the association of newly formed geopolymer and recycled aggregates behaves as a binding matrix. Mortars based on matrices incorporating $50 \mathrm{wt} . \%$ of recycled geopolymers exhibit strengths of around $50 \mathrm{MPa}$, a performance which meets the requirements for construction materials.

- An anchoring model by interfacial chemical bonding within the new matrices has been proposed to explain the good adhesion properties between the newly formed geopolymer and the geopolymer waste aggregates.

Author Contributions: Conceptualization, A.S.; methodology, R.M. and A.S.; validation, N.L., A.A. and R.M.; formal analysis, N.L.; investigation, R.H.; resources, M.O.T.; data curation, R.H.; writing—original draft preparation, R.H., R.M.; writing—review and editing, M.O.T., R.M. and M.G.; visualization, R.H.; supervision, A.A.; funding acquisition, R.M. and M.G. All authors have read and agreed to the published version of the manuscript.

Funding: This research is supported through the R\&D Initiative-Appel à projets autour des phosphates APPHOS-sponsored by OCP, OCP Foundation, R\&D OCP, Mohammed VI Polytechnic University, National Center of Scientific and Technical Research CNRST, Ministry of Higher Education, Scientific Research and Professional Training of Morocco MESRSFC under the project ID * MAT-MOS-01/2017*.

Conflicts of Interest: The authors declare no conflict of interest.

\section{References}

1. Benhelal, E.; Zahedi, G.; Shamsaei, E.; Bahadori, A. Global Strategies and Potentials to Curb $\mathrm{CO}_{2}$ Emissions in Cement Industry. J. Clean. Prod. 2013, 51, 142-161. [CrossRef]

2. Rahman, A.; Rasul, M.G.; Khan, M.M.K.; Sharma, S. Impact of Alternative Fuels on the Cement Manufacturing Plant Performance: An Overview. Procedia Eng. 2013, 56, 393-400. [CrossRef]

3. Turner, L.K.; Collins, F.G. Carbon Dioxide Equivalent $\left(\mathrm{CO}_{2}-\mathrm{e}\right)$ Emissions: A Comparison between Geopolymer and OPC Cement Concrete. Constr. Build. Mater. 2013, 43, 125-130. [CrossRef]

4. Carreño-Gallardo, C.; Tejeda-Ochoa, A.; Perez-Ordonez, O.I.; Ledezma-Sillas, J.E.; Lardizabal-Gutierrez, D.; Prieto-Gomez, C.; Valenzuela-Grado, J.A.; Robles Hernandez, F.C.; Herrera-Ramirez, J.M. In the $\mathrm{CO}_{2}$ Emission Remediation by Means of Alternative Geopolymers as Substitutes for Cements. J. Environ. Chem. Eng. 2018, 6, 4878-4884. [CrossRef]

5. Davidovits, J. Geopolymers-Inorganic Polymeric New Materials. J. Therm. Anal. 1991, 37, 1633-1656. [CrossRef]

6. Duxson, P.; Fernández-Jiménez, A.; Provis, J.L.; Lukey, G.C.; Palomo, A.; van Deventer, J.S.J. Geopolymer Technology: The Current State of the Art. J. Mater. Sci. 2007, 42, 2917-2933. [CrossRef]

7. Yao, X.; Zhang, Z.; Zhu, H.; Chen, Y. Geopolymerization Process of Alkali-Metakaolinite Characterized by Isothermal Calorimetry. Thermochim. Acta 2009, 493, 49-54. [CrossRef]

8. Rashad, A.M. A Comprehensive Overview about the Influence of Different Admixtures and Additives on the Properties of Alkali-Activated Fly Ash. Mater. Des. 2014, 53, 1005-1025. [CrossRef]

9. Rashad, A.M. Alkali-Activated Metakaolin: A Short Guide for Civil Engineer-An Overview. Constr. Build. Mater. 2013, 41, 751-765. [CrossRef] 
10. Provis, J.L.; van Deventer, J.S.J. Geopolymers: Structures, Processing, Properties and Industrial Applications; Elsevier: Amsterdam, The Netherlands, 2009; ISBN 9781845694494.

11. Jiang, C.; Wang, A.; Bao, X.; Ni, T.; Ling, J. A Review on Geopolymer in Potential Coating Application: Materials, Preparation and Basic Properties. J. Build. Eng. 2020, 32, 101734. [CrossRef]

12. Aboulayt, A.; Gounni, A.; El Alami, M.; Hakkou, R.; Hannache, H.; Gomina, M.; Moussa, R. Thermo-Physical Characterization of a Metakaolin-Based Geopolymer Incorporating Calcium Carbonate: A Case Study. Mater. Chem. Phys. 2020, $252,123266$. [CrossRef]

13. Detphan, S.; Chindaprasirt, P. Preparation of Fly Ash and Rice Husk Ash Geopolymer. Int. J. Miner. Metall. Mater. 2009, 16, 720-726. [CrossRef]

14. Deb, P.S.; Nath, P.; Sarker, P.K. The Effects of Ground Granulated Blast-Furnace Slag Blending with Fly Ash and Activator Content on the Workability and Strength Properties of Geopolymer Concrete Cured at Ambient Temperature. Mater. Des. 2014, 62, 32-39. [CrossRef]

15. Kumar, A.; Kumar, S. Development of Paving Blocks from Synergistic Use of Red Mud and Fly Ash Using Geopolymerization. Constr. Build. Mater. 2013, 38, 865-871. [CrossRef]

16. Hamdane, H.; Tamraoui, Y.; Mansouri, S.; Oumam, M.; Bouih, A.; El Ghailassi, T.; Boulif, R.; Manoun, B.; Hannache, H. Effect of Alkali-Mixed Content and Thermally Untreated Phosphate Sludge Dosages on Some Properties of Metakaolin Based Geopolymer Material. Mater. Chem. Phys. 2020, 248, 122938. [CrossRef]

17. Luhar, S.; Cheng, T.W.; Nicolaides, D.; Luhar, I.; Panias, D.; Sakkas, K. Valorisation of Glass Waste for Development of Geopolymer Composites-Mechanical Properties and Rheological Characteristics: A Review. Constr. Build. Mater. 2019, 220, 547-564. [CrossRef]

18. Aboulayt, A.; Souayfan, F.; Roziere, E.; Jaafri, R.; Cherki El Idrissi, A.; Moussa, R.; Justino, C.; Loukili, A. Alkali-Activated Grouts Based on Slag-Fly Ash Mixtures: From Early-Age Characterization to Long-Term Phase Composition. Constr. Build. Mater. 2020, 260, 120510. [CrossRef]

19. Dadsetan, S.; Siad, H.; Lachemi, M.; Sahmaran, M. Construction and Demolition Waste in Geopolymer Concrete Technology: A Review. Mag. Concr. Res. 2019, 71, 1232-1252. [CrossRef]

20. Ji, Z.; Pei, Y. Immobilization Efficiency and Mechanism of Metal Cations $\left(\mathrm{Cd}^{2+}, \mathrm{Pb}^{2+}\right.$ and $\left.\mathrm{Zn}^{2+}\right)$ and $\mathrm{Anions}\left(\mathrm{AsO}_{4}{ }^{3-}\right.$ and $\mathrm{Cr}_{2} \mathrm{O}_{7}{ }^{2-}$ ) in Wastes-Based Geopolymer. J. Hazard. Mater. 2020, 384. [CrossRef] [PubMed]

21. Li, Q.; Sun, Z.; Tao, D.; Xu, Y.; Li, P.; Cui, H.; Zhai, J. Immobilization of Simulated Radionuclide 133Cs+ by Fly Ash-Based Geopolymer. J. Hazard. Mater. 2013, 262, 325-331. [CrossRef] [PubMed]

22. Nath, S.K. Fly Ash and Zinc Slag Blended Geopolymer: Immobilization of Hazardous Materials and Development of Paving Blocks. J. Hazard. Mater. 2020, 387. [CrossRef]

23. Akbarnezhad, A.; Huan, M.; Mesgari, S.; Castel, A. Recycling of Geopolymer Concrete. Constr. Build. Mater. 2015, 101, 152-158. [CrossRef]

24. Zhu, P.; Hua, M.; Liu, H.; Wang, X.; Chen, C. Interfacial Evaluation of Geopolymer Mortar Prepared with Recycled Geopolymer Fine Aggregates. Constr. Build. Mater. 2020, 259, 119849. [CrossRef]

25. Gharzouni, A.; Vidal, L.; Essaidi, N.; Joussein, E.; Rossignol, S. Recycling of Geopolymer Waste: Influence on Geopolymer Formation and Mechanical Properties. Mater. Des. 2016, 94, 221-229. [CrossRef]

26. Sun, Z.; Vollpracht, A. One Year Geopolymerisation of Sodium Silicate Activated Fly Ash and Metakaolin Geopolymers. Cem. Concr. Compos. 2019, 95, 98-110. [CrossRef]

27. Aboulayt, A.; Riahi, M.; Ouazzani Touhami, M.; Hannache, H.; Gomina, M.; Moussa, R. Properties of Metakaolin Based Geopolymer Incorporating Calcium Carbonate. Adv. Powder Technol. 2017, 28, 2393-2401. [CrossRef]

28. Aboulayt, A.; Riahi, M.; Anis, S.; Touhami, M.O.; Moussa, R. Rheological Behavior of a Fresh Geopolymer Based on Metakaolin: Effect of the Introduction of Calcium Carbonate. Int. J. Innov. Appl. Stud. 2014, 7, 1170-1177.

29. Mo, B.H.; Zhu, H.; Cui, X.M.; He, Y.; Gong, S.Y. Effect of Curing Temperature on Geopolymerization of Metakaolin-Based Geopolymers. Appl. Clay Sci. 2014, 99, 144-148. [CrossRef]

30. ASTM. Inernational Standard Test Methods for Flexural Properties of Unreinforced and Reinforced Plastics and Electrical Insulating Materials. In ASTM D790-07; CiNii: Tokyo, Japan, 2007.

31. Aboulayt, A.; Jaafri, R.; Samouh, H.; Cherki El Idrissi, A.; Roziere, E.; Moussa, R.; Loukili, A. Stability of a New Geopolymer Grout: Rheological and Mechanical Performances of Metakaolin-Fly Ash Binary Mixtures. Constr. Build. Mater. 2018, 181, 420-436. [CrossRef]

32. Gholampour, A.; Ho, V.D.; Ozbakkaloglu, T. Ambient-Cured Geopolymer Mortars Prepared with Waste-Based Sands: Mechanical and Durability-Related Properties and Microstructure. Compos. Part B Eng. 2019, 160, 519-534. [CrossRef]

33. Rashad, A.M. An Exploratory Study on Alkali-Activated Slag Blended with Quartz Powder under the Effect of Thermal Cyclic Loads and Thermal Shock Cycles. Constr. Build. Mater. 2014, 70, 165-174. [CrossRef]

34. Rashad, A.M.; Ouda, A.S. An Investigation on Alkali-Activated Fly Ash Pastes Modified with Quartz Powder Subjected to Elevated Temperatures. Constr. Build. Mater. 2016, 122, 417-425. [CrossRef]

35. Lu, J.X.; Poon, C.S. Use of Waste Glass in Alkali Activated Cement Mortar. Constr. Build. Mater. 2018, 160, 399-407. [CrossRef]

36. Wang, C.C.; Wang, H.Y.; Chen, B.T.; Peng, Y.C. Study on the Engineering Properties and Prediction Models of an Alkali-Activated Mortar Material Containing Recycled Waste Glass. Constr. Build. Mater. 2017, 132, 130-141. [CrossRef] 
37. Zhang, Z.; Wang, H.; Zhu, Y.; Reid, A.; Provis, J.L.; Bullen, F. Using Fly Ash to Partially Substitute Metakaolin in Geopolymer Synthesis. Appl. Clay Sci. 2014, 88-89, 194-201. [CrossRef]

38. Hajimohammadi, A.; Ngo, T.; Kashani, A. Glass Waste versus Sand as Aggregates: The Charactersistics of the Evolving Geopolymer Binders. J. Clean. Prod. 2018, 193, 593-603. [CrossRef]

39. Muñiz-Villarreal, M.S.; Manzano-Ramírez, A.; Sampieri-Bulbarela, S.; Gasca-Tirado, J.R.; Reyes-Araiza, J.L.; Rubio-Ávalos, J.C.; Pérez-Bueno, J.J.; Apatiga, L.M.; Zaldivar-Cadena, A.; Amigó-Borrás, V. The Effect of Temperature on the Geopolymerization Process of a Metakaolin-Based Geopolymer. Mater. Lett. 2011, 65, 995-998. [CrossRef]

40. Cho, Y.K.; Yoo, S.W.; Jung, S.H.; Lee, K.M.; Kwon, S.J. Effect of Na2O Content, SiO2/Na2O Molar Ratio, and Curing Conditions on the Compressive Strength of FA-Based Geopolymer. Constr. Build. Mater. 2017, 145, 253-260. [CrossRef]

41. Nath, S.K.; Kumar, S. Reaction Kinetics of Fly Ash Geopolymerization: Role of Particle Size Controlled by Using Ball Mill. Adv. Powder Technol. 2019, 30, 1079-1088. [CrossRef]

42. Cai, J.; Li, X.; Tan, J.; Vandevyvere, B. Thermal and Compressive Behaviors of Fly Ash and Metakaolin-Based Geopolymer. J. Build. Eng. 2020, 30, 101307. [CrossRef]

43. Durak, U.; İlkentapar, S.; Karahan, O.; Uzal, B.; Atiş, C.D. A New Parameter Influencing the Reaction Kinetics and Properties of Fly Ash Based Geopolymers: A Pre-Rest Period before Heat Curing. J. Build. Eng. 2020, 102023. [CrossRef]

44. Zhang, L.; Zhang, F.; Liu, M.; Hu, X. Novel Sustainable Geopolymer Based Syntactic Foams: An Eco-Friendly Alternative to Polymer Based Syntactic Foams. Chem. Eng. J. 2017, 313, 74-82. [CrossRef]

45. Pelisser, F.; Guerrino, E.L.; Menger, M.; Michel, M.D.; Labrincha, J.A. Micromechanical Characterization of Metakaolin-Based Geopolymers. Constr. Build. Mater. 2013, 49, 547-553. [CrossRef]

46. Kuenzel, C.; Li, L.; Vandeperre, L.; Boccaccini, A.R.; Cheeseman, C.R. Influence of Sand on the Mechanical Properties of Metakaolin Geopolymers. Constr. Build. Mater. 2014, 66, 442-446. [CrossRef]

47. Görhan, G.; Kürklü, G. The Influence of the NaOH Solution on the Properties of the Fly Ash-Based Geopolymer Mortar Cured at Different Temperatures. Compos. Part B Eng. 2014, 58, 371-377. [CrossRef]

48. Kaur, M.; Singh, J.; Kaur, M. Synthesis of Fly Ash Based Geopolymer Mortar Considering Different Concentrations and Combinations of Alkaline Activator Solution. Ceram. Int. 2018, 44, 1534-1537. [CrossRef] 